\title{
Large-scale simulation of the human cranial arterial tree: utility in hydrocephalus
}

\author{
Tomer Anor*1, Leopold Grienberg ${ }^{2}$, Joseph R Madsen ${ }^{1}$ and \\ George E Karniadakis ${ }^{2}$
}

\begin{abstract}
Address: ${ }^{1}$ Department of Neurosurgery, Children's Hospital Boston, Harvard Medical School, Boston, MA 02115, USA and 2Division of Applied Mathematics. Brown University. Providence, RI 02912, USA

Email: Tomer Anor* - tomer.anor@childrens.harvard.edu

* Corresponding author
\end{abstract}

from 52nd Annual Meeting of the Society for Research into Hydrocephalus and Spina Bifida

Providence, RI, USA. II-14 June 2008

Published: 3 February 2009

Cerebrospinal Fluid Research 2009, 6(SuppI I):S48 doi:I0.II86/I743-8454-6-SI-S48

This abstract is available from: http://www.cerebrospinalfluidresearch.com/content/6/SI/S48

(c) 2009 Anor et al; licensee BioMed Central Ltd.

\section{Background}

Recent work in hydrocephalus modelling has drawn attention to the potential role of disruption of a pulsation absorber mechanism in the intracranial compartment. Therefore, characterization of cerebral hemodynamics is essential for understanding complex intracranial dynamics under normal and diseased conditions, diagnosing and treating patients suffering from hydrocephalus, and designing medical devices. To this end, we have developed a procedure for generating physiologically accurate models of the cerebral hemodynamics by coupling clinical data and the multiscale modelling approach.

\section{Materials and methods}

Our strategy for the cranial arterial tree modelling is to include all arteries that can be accurately imaged using conventional medical imaging techniques, such as Magnetic-Resonance Angiography (MRA) and Computed Tomography (CT) in the computational domain. The "sub-pixel" dynamics described by microvascular network act as "closure" to the large-scale arterial dynamics. Patient-specific anatomical models are constructed from high resolution MRA and CT images covering the volume of interest. Due to the geometric complexity of the cranial arterial system, we employ high-order spectral/hp element methods for solving the governing flow equations. Highly scalable parallel implementation allows the dramatic reduction of overall computation time of the 3D large- scale simulations. In our models we account for the cerebral autoregulation mechanism by prescribing a scalable and efficient type of pressure boundary condition applicable to flow domains with multiple outlets. This method allows us to impose accurately and in a straight-forward manner in-vivo measured flow rates at terminal outlets. Measuring the flow rate, unlike measuring the pressure, is a straightforward procedure that is performed using non-invasive techniques. Two such techniques that we employ are Transcranial Doppler Ultrasound (TCD) and Phase-contrast MRI. Volumetric flow rates are obtained by integration of the velocities throughout a lumen cross-sectional area defined by its boundary.

\section{Results}

Consistent with previous findings, our 3D simulations of human intracranial dynamics predict cerebral hypoperfusion and elevated resistivity and pulsatility indices in patients with hydrocephalus. Our models can be utilized to predict the hemodynamic effects and outcomes of clinical interventions such as shunting and endoscopic third ventriculostomy. In developing a model of this complexity, validation is critical. The numerical results are consistent with observed data obtained from dog and human measurements. 


\section{Conclusion}

Human intracranial dynamics models are powerful research tools to enhance the understanding of pathophysiological mechanisms in hydrocephalus and provide realistic parameters for comparing patients with normal controls.

Publish with Bio Med Central and every scientist can read your work free of charge

"BioMed Central will be the most significant development for disseminating the results of biomedical research in our lifetime. " Sir Paul Nurse, Cancer Research UK

Your research papers will be:

- available free of charge to the entire biomedical community

- peer reviewed and published immediately upon acceptance

- cited in PubMed and archived on PubMed Central

- yours - you keep the copyright

Submit your manuscript here:

http://www.biomedcentral.com/info/publishing_adv.asp 